\title{
ASPECTOS NEUROLóGICOS DA POLICITEMIA VERA
}

\author{
ROBERTO MELARAGNO FILHO : \\ JOSÉ ANTONIO LEVY * *
}

As repercussões neurológicas da policitemia vera são freqüentes, dando lugar a sintomas de ordem geral e focal.

Já Osler 22 (1903), ao descrever a nova entidade clínica - caracterizada por cianose, policitemia e aumento do baço — referia, entre os sintomas principais, a cefaléia e a vertigem. Lucas ${ }^{19}$, ao fazer uma revisão dos 197 casos de policitemia descritos até 1912, assinalava que o sistema nervoso é afetado em grande número de casos, tendo sido encontrados variados sintomas neurológicos: "zumbidos, apreensão, nervosismo, excitabilidade, delírio, hipocondria, insônia, diminuição dos reflexos, atrofias musculares, parestesias, ataques coreiformes e epileptiformes, fibrilações musculares, tremor, paralisias, hemiplegias, afasias, distúrbios da palavra, sensação de calor na cabeça, perdas de consciência, sensação sincopal, etc.". Christian ₹ encontrou sintomas neurológicos em 8 de 10 casos estudados, sendo a cefaléia e a vertigem as queixas mais freqüentes. Dameshek e Henstell ${ }^{8}$, em 20 casos, verificaram ser a multiplicidade de sintomas o fator mais constante. Pollock ${ }^{23}$ descreveu dois casos de coréia e policitemia, um próprio e um de Bordachzi, sendo de opinião que a sintomatologia dêsses dois casos era determinada por hemorragia ou trombose. Um caso de policitemia com crises de cefaléia do tipo da enxaqueca oftálmica associada à diplopia foi relatado por Weber ${ }^{31}$; a literatura registra outros três casos com cefaléia de tipo hemicrania em pacientes policitêmicos (Dameshek e Henstell ${ }^{8}$ ).

Brown e Giffin ${ }^{1}$ consideram três tipos de sintomas na policitemia vera: os relacionados à distensão vascular e ao aumento da viscosidade sangüínea (vertigem, cefaléia, hemorragias e alterações da côr da pele); os relacionados a modificações orgânicas dos vasos sangüíneos (distúrbios cerebrais, enfartes e claudicação); os relacionados a distúrbios do metabolismo (perda de pêso, polidipsia, exaustão e intolerância ao calor e ao frio). Chalgren e Johnson ${ }^{5}$ consideram a cefaléia, vertigem, fadiga e fraqueza como os sintomas mais freqüentes da policitemia, sendo também comuns os distúrbios visuais, as parestesias e as dôres; êstes mesmos autores ${ }^{6}$ estudaram dois casos de neurite periférica generalizada secundários à policitemia vera e referem

Trabalho da Clínica Neurológica da Fac. Med. da Univ. de São Paulo (Prof. A. Tolosa).

* Livre-Docente.

** Assistente extranumerário. 
que, embora êstes casos sejam raros, os sintomas subjetivos de adormecimentos e formigamentos nas extremidades são comuns. Roger e Olmer ${ }^{24}$, em extenso capítulo sôbre as "síndromes neuro-globúlicas", incluíram, na parte referente à sintomatologia: algias (sendo a cefaléia a mais freqüente), astenia com fatigabilidade intelectual, vertigens, complicações cerebrais motoras (geralmente hemiplegias) e psíquicas; êstes autores consideram as manifestaçōes medulares como excepcionais, o que explicam pela resistência do tecido medular aos distúrbios circulatórios em virtude das numerosas anastomoses. Tinney e col. ${ }^{28}$, em 163 casos de policitemia vera, encontraram sintomas relacionados ao sistema nervoso em $127(78 \%)$, sendo a cefaléia o sintoma mais comum, vindo logo a seguir a vertigem, a fraqueza e os distúrbios visuais. Os sintomas visuais estão entre os mais comuns; progressivo e gradual borramento e diminuição da visão podem ser os primeiros sintomas e, em virtude do aparecimento de escotomas luminosos, freqüentemente é feito o diagnóstico de enxaqueca ${ }^{5}$.

Os primeiros sintomas, ocorrem geralmente entre os 50 e os 60 anos de idade, registrando-se poucos casos antes dos 30 anos ${ }^{1}$. Lawrence e col. ${ }^{17}$ referem não haver predominância de nacionalidade ou grupo racial; em 63 pacientes por êles estudados $57 \%$ eram homens.

Além de constituir a causa de muitos sintomas neurológicos, a policitemia vera é considerada, por muitos autores, como de origem neurogênica. em virtude do seu aparecimento em vários casos de encefalite epidêmica ${ }^{26}$. Assim, Ferraro e Sherwood ${ }^{12}$ admitem que a encefalite letárgica, pela destruição dos centros vegetativos, é diretamente responsável pela policitemia. Com o intuito de investigar esta hipótese patogênica, Schulof e Matthies ${ }^{26}$ lesaram várias áreas encefálicas de coelhos, verificando significativo aumento no número de hemácias circulantes exclusivamente naqueles casos em que as lesões foram feitas nas zonas em que se situam os centros vegetativos diencefálicos. Assim, pelo menos alguns casos de policitemia poderiam ser imputados a alterações dos centros vegetativos cerebrais.

De outra parte, têm sido relatados vários casos de hemangioblastoma da fossa posterior associados à policitemia; assim, Woolsey 33 relatou a verificação de hemangioblastoma do cerebelo em caso de policitemia no qual houve remissão completa após a retirada do tumor. Carpenter, Schwartz e Walker ${ }^{3}$ referem dois casos e Walker ${ }^{30}$ um outro, de policitemia nos quais a contagem de hemácias voltou ao normal após a extirpação cirúrgica de hemangioblastomas subtentoriais. Para Walker ${ }^{30}$, o tipo patológico de tumor provàvelmente não tem importância etiológica na policitemia, pois, em 14 outros hemangioblastomas do cerebelo não havia qualquer evidência da moléstia hemática. Drew e Grant ${ }^{10}$ relatam um caso de policitemia com sintomas neurológicos, sendo encontrado, na operação, um hematoma crônico subdural, o qual foi removido com grande melhora dos sintomas; êstes autores ficaram na dúvida se o hematoma teria sido causa ou efeito da policitemia. Oppenheimer ${ }^{21}$ refere um caso de policitemia no qual um meduloblastoma cerebelar foi encontrado na autópsia; Meiner 20 encontrou um glio- 
blastoma multiforme difuso da circunvolução pós-central direita e dos giros angular e supramarginal em paciente policitêmico.

Reunimos, no presente trabalho, os casos de policitemia vera (8) observados no Hospital das Clínicas da Universidade de São Paulo sôbre um total de 147.749 doentes internados desde janeiro de 1944 até junho de 1955 .

Caso 1 - C. D., sexo masculino, branco, 50 anos, internado na $3^{a}$ Clinica Médica (Prof. Almeida Prado), em 20-9-1950 (Reg. 176.408). História de 3 anos e meio, queixando-se o paciente de cefaléia, tonturas, dôres abdominais, urina avermelhada, dôres lombares e evacuações liqüidas com sangue vivo. Tensão arterial 120x70; facies pletórica, mucosas muito coradas, leve cianose dos lábios, congestāo da conjuntiva ocular; artérias periféricas endurecidas, aumento de calibre das veias visíveis nas porções superiores do abdome; baço palpável; musculatura hipotrófica. Exame somático do sistema nervoso, normal. Fundo de ôlho normal. Exame hematológico: 6.000 .000 de hemácias por $\mathrm{mm}^{3}$; hemoglobina $109 \%=17 \mathrm{~g} \%$; valor globular 0,9 ; 9.800 leucócitos por $\mathrm{mm}^{3}$. Hematócrito 60\%. Tempo de coagulação 8 segundos; tempo de sangria 1 minuto e 30 segundos. Prova de Hanger fortemente positiva. Mielograma: aumento de eosinófilos, anaplasia granulocítica, hiperplasia eritroblástica com anaplasia; sinais de solicitação da série vermelha. Esplenograma: pequena quantidade de células granulocíticas mielóides imaturas; aumento de eosinófilos; não há focos de eritropoiese. Biópsia de figado: tecido normal.

Caso 2 - Q. P., sexo masculino, 66 anos, branco, internado na $3^{\sharp}$ Clinica Médica (Prof. Almeida Prado) em 6-3-1948 (Reg. 101.016). O paciente refere história de 2 anos, com eritrodermia, parestesias, dôres nos pés e edemas, além de cefaléia e zumbidos nos ouvidos. O exame mostrou: facies intensamente corado; cianose; hipertermia e grande turgescência venosa na perna direita e, em menor grau, também na perna esquerda; figado palpável; baço não percutivel nem palpável. O exame neurológico nada revelou de anormal, a não ser hipotonia generalizada. Exame oftalmoscópico: papilas hiperemiadas de contornos pouco nitidos; veias muito dilatadas; artérias com reflexo luminoso central aumentado e algumas cruzes de Gunn; ausência de hemorragias ou de exsudatos. Exame hematológico: 6.500,000 hemácias por $\mathrm{mm}^{3}$; hemoglobina $21,9 \%$; 30.000 leucócitos por $\mathrm{mm}^{3}$. Mielograma: medula em hiperplasia global, aumento da granulocitopoiese com maturação conservada da eritropoiese; predominância de eritroblastos basófilos e figuras de mitose freqüentes nesse série; megacariócitos aumentados com franca plaquetogenese. Eletrocardiograma: onda $\mathbf{P}$ de tipo pulmonar (sobrecarga direita). Oscilometria dos membros inferiores: redução dos indices oscilométricos em todos os niveis de ambas as pernas.

CASo 3 - o. G., sexo masculino, 48 anos, branco, brasileiro, internado na Clínica de Moléstias Infecciosas (Prof. J. Alves Meira) em maio de 1952 (Reg. 295.379). Há 12 anos o paciente vinha apresentando dôres abdominais com diarréia e fezes prêtas, pêso no hemitórax esquerdo, sensação subjetiva de febre, tonturas, astenia, cefaléia e visão xantópsica. A cefaléia, localizada na região frontal, era de intensidade variável; as tonturas, de incidência diária, obrigavam por vẽzes a imobilização do paciente, a fim de evitar desequilibração e queda. O paciente relaciona seus distúrbios a um traumatismo (fulguração), ao qual se seguira hemiplegia esquerda. Exame clínico - Facies pletórica; tensão arterial 135x85; exantema e petéquias principalmente nos membros; estase jugular bilateral; esplenomegalia; ligeira hipotrofia da perna direita, particularmente da pantorrilha, não sendo palpáveis as artérias tibial posterior e pediosa nesse lado. Exame somático do sistema nervoso negativo. Exame oftalmoscópico: papilas normais, veias túrgidas. Eletrencefalograma normal. Exame hematológico: 6.300 .000 hemácias por $\mathrm{mm}^{3}$; hemoglobina $15,7 \mathrm{~g} \%=98 \%$; valor globular 0,$8 ; 9.100$ leucócitos por $\mathrm{mm}^{3}$; neutrofilia com desvio à esquerda, eosinofilia, neutrófilos com granulaçōes tóxicas; 450.000 plaquetas por $\mathrm{mm}^{3}$ (Fonio). Tempo de coagulaçĩo 8 minutos; tempo de sangria 3 minutos. Pesquisa de sangue 
nas fezes positiva. Mielograma: medula normocelular; relação $\mathrm{G} / \mathrm{E}$ aproximadamente 2:1; hiperplasia relativa da série vermelha; na série granulocitica, aumento de promielócitos e metamielócitos; na série vermelha, hiperplasia eritroblástica com maturação conservada, megacariócitos normais em plaquetopoiese. Esplenograma: riqueza celular aumentada, grande número de células do tipo linfóide (90\% do total), alguns promielócitos neutrófilos, eosinófilos, algumas células reticulares e mastzellen, raros eritroblastos, caracteres de reaçāo celular linfóide com eosinofilia e leve solicitaçāo da granulopoiese, alguns megacariócitos, grande quantidade de plaquetas.

Caso 4 - V. C., sexo masculino, 48 anos, branco, internado na 1: Clinica Médica (Prof. Ulhôa Cintra) em 15-1-1953 (reg. 314.448). O paciente vinha sentindo, há 2 anos, cefaléias freqüentes, sobretudo à tarde; 4 meses antes da internação acordou com forte cefaléia e dificuldade para falar e para deglutir alimentos sólidos; após 3 dias êsses distúrbios melhoraram, mas 3 meses depois se repetiram. Ao ser internado, ainda existia disartria e sialorréia abundante. Exame clínico: grande congestão da face, do pescoço e das conjuntivas; artérias de paredes espessadas; tensão arterial 170x120; sôpro sistólico nos focos aórtico e mitral; fígado palpável; baço palpável. O exame somático do sistema nervoso nada revelou de anormal, além da disartria. Exame oftalmológico: em OD borramenta dos bordos da papila, sem alterações maculares; em OE mesmo quadro oftalmoscópico, além de hemorragia superficial no lado nasal inferior da retina. Exame do.liqüido céfalo-raquidiano normal. Exame hematológico: 5.800 .000 hemácias por $\mathrm{mm}^{3}$; valor globular 0,8 ; hemoglobina $16 \mathrm{~g} \%=$ 100\%; 8.200 leucócitos por $\mathrm{mm}^{3}$. Mielograma: medula normocelular, leve hiperplasia da série vermelha, leve aumento de linfócitos. Hematócrito $58 \%$. Pêso corporal $77,600 \mathrm{~kg}$; altura $1,75 \mathrm{~m}$. Volemia: plasma $4.703 \mathrm{mg}$; glóbulos $6.494 \mathrm{ml}$; sangue total $11.197 \mathrm{ml}$.

CAşo 5 - I. A., 61 anos, sexo masculino, branco, polonês, internado na 2a Clínica Cirúrgica (Prof. Edmundo Vasconcelos) em 23-12-1944 (reg. 5.784). História de 10 anos, iniciando-se com eritema no rosto, progressivamente acentuado. Um ano antes da internação, o paciente principiou a apresentar epistaxes freqüentes, queixando-se de cefaléia de regular intensidade, sempre com pequena duração, além de irritabilidade nervosa, astenia e, raramente, dôres nos membros. Exame clinico: facies avermelhada, mucosas de côr vermelho-arroxeado; esplenomegalia. Exame oftalmoscópico: papilas hiperemiadas, artérias sem alterações, veias dilatadas e tortuosas, com reflexo normal alargado. Biópsia do figado: normal. Exame hematológico: 7.200 .000 hemácias por $\mathrm{mm}^{3}$; hemoglobina $22 \mathrm{~g} \%=140 \%$; valor globular 0,9; 7.080 leucócitos por $\mathrm{mm}^{3}$; desvio para a esquerda. Pressão venosa (safena externa), $10 \mathrm{~cm}$ de água. Velocidade circulatória: tempo braço-lingua $18 \mathrm{seg}$ (dalichol); tempo braço-pulmão $8 \mathrm{seg}$ (éter). Volemia: volume total de sangue $6.177 \mathrm{ml}$ ou $107 \mathrm{ml}$ por quilo de pêso (normal 65); volume total de plasma $388 \mathrm{ml}$ ou $67 \mathrm{ml}$ por quilo de pêso (normal 35); massa total de eritrócitos $2.213 \mathrm{mI}$ ou $38 \mathrm{ml}$ por quilo de pêso (normal 30 ). Contagem de plaquetas: 355.000 por $\mathrm{mm}^{3}$ (Fonio). Mielograma: na série branca, hiperplasia global com desvio para as formas mais imaturas; na série vermelha, intensa hiperplasia global e relativa; os elementos eritroblásticos representam $45 \%$, isto é, cêrca da metade das células da medula (normalmente representam apenas 1/3), predominando os eritroblastos ortocromáticos, isto é, há maturação completa e perfeita com grande cito-emissão e até retenção dêstes elementos no parênquima mielóide, megacariócitos presentes, normais e raros. Esplenograma: mielopoiese no baço, hiperplasia de elementos mielóides, solicitação das séries branca e vermelha.

Nos 5 casos até aqui relatados havia, em comum, fenômenos subjetivos de sofrimento encefálico, sobretudo de cefaléia, sem que, no momento do exame, fôssem evidenciados sinais neurológicos focais. No caso 3 , havia referências anamnésticas à hemiplegia esquerda transitória, que ocorrera após um traumatismo; no caso 4, a paciente referia ter apresentado, por duas vê- 
zes e sob forma de icto não apoplético, disartria e disfagia transitórias. acompanhadas de exacerbação da cefaléia.

Dêstes 5 casos $\in m$ que o exame neurológico não revelou sinais focais, o exame cftalmoscópico foi normal em um, não foi feito em outro; êste exame mostrou nítidas alteraçōes em três casos. Êstes distúrbios consistiam, essencialmente, em congestão venosa retiniana. No único dêstes 5 casos em que foi realizado (caso 3 ), o eletrencefalograma se revelou normal.

Caso 6 - A. T., sexo feminino, 41 anos, internada no Serviço de Nutrição (Prof. A. Ulhôa Cintra) em 5-2-1945 (reg. 6.506). História de 20 anos, iniciando-se com astenia, hemorragias freqüentes gengivais e retais, tonturas e cefaléia. Trēs meses antes da internação, sofreu pronunciada hemorragia uterina a que se seguiu hemiparesia esquerda, a qual regrediu totalmente. Exame clínico: tensão arterial 110x50; mãos e rosto cianosados; esplenomegalia. Exame neurológico normal. Fundos oculares sem alterações. Exame hematológico: 6.400 .000 hemácias por $\mathrm{mm}^{3} ; 8.640$ leucócitos por $\mathrm{mm}^{3}$; hemoglobina $16 \mathrm{~g} \%=100 \%$; valor globular 0,7 . Volume de sangue circulante aumentado, tanto em relação ao plasma $(66,5 \mathrm{ml}$ por quilo de pêso) como ao sangue total (103 $\mathrm{ml}$ por quilo de pêso) e aos eritrócitos (37 $\mathrm{ml}$ por quilo de pêso).

A paciente teve alta em fevereiro de 1945, voltando ao ambulatório ulteriormente, em 1947, com queixa de cefaléias intensas e freqüentes. Em setembro de 1948 sofreu um icto a que se seguiu hemiplegia direita e distúrbios da linguagem. Foi então encaminhada à Clínica Neurológica, onde o exame revelou: tensão arterial 230×140; discreta hemiparesia direita, sendo o déficit mais acentuado na mão; coordenaçāo muscular normal; reflexos simétricos; sinal de Rossolimo à direita; sensibilidade normal; reflexos pupilares normais.

Neste caso houve, ao lado dos sintomas nervosos gerais, nitida lesão isquêmica do território superficial da artéria cerebral média esquerda, cujos sintomas remitiram parcialmente. $\dot{E}$ interessante assinalar, neste caso, a normalidade do exame oftalmoscópico.

Caso 7 - F. K. M., sexo feminino, 56 anos, branca, internada no Serviço de Neurologia em 2-8-1954 (reg. 382.233). Há 6 anos a paciente vinha tendo sensação de calor no rosto e vertigens rotatórias relacionadas com a movimentação da cabeça. Um mês antes da internação teve dor lombar que se irradiava para o abdome e para os membros inferiores durando algumas horas, após as quais os membros inferiores ficaram paralisados; no mesmo dia teve retenção de urina. Em seus antecedentes a paciente refere que 19 anos antes tivera intensa crise de cefaléia, sendo nessa ocasião tratada por meio de várias sangrias. Exame clínico: tensão arterial 120x80; pequenas sufusōes hemorrágicas na pele, provocáveis por traumatismos minimos; hépato e esplenomegalia. Exame neurológico: paraplegia crural completa, motora e sensitiva, com abolição de tôdas as formas de sensibilidade abaixo de $T_{11}$, com faixa de hiperestesia a êsse nivel; arreflexia superficial e profunda nos membros inferiores; reflexos profundos presentes e normais nos membros superiores, abolição dos reflexos cutâneo-abdominais; hipotrofia muscular nos músculos quadriceps e adutores das côxas, assim como nos músculos das mãos; fôrça muscular nula nos membros inferiores; diminuida nos membros superiores, principalmente nas māos; taxia normal nos membros superiores; ausência de qualquer sinal cerebelar; nervos cranianos normais. Fundo de ôlho normal. Exames complementares — Exame do liqüido céfaloraquidiano: punção lombar; pressão inicial $18 \mathrm{~cm}$ de água (manômetro de Claude); boa permeabilidade às provas de Stookey; líquor lípido e discretamente xantocrômico; 4 células por $\mathrm{mm}^{3}$ (linfócitos); $30 \mathrm{mg}$ de proteínas por $100 \mathrm{ml} ; 720 \mathrm{mg}$ de cloretos por $100 \mathrm{ml} ; 83 \mathrm{mg}$ de glicose por $100 \mathrm{ml}$; reaçōes de Pandy e Nonne negativas; reaçōes de Wassermann, Steinfeld e Weimberg negativas. Novo exame de liquor feito 
30 dias depois resultou inteiramente normal. Radiografias da coluna tóraco-lombar: processo de ósteo-artrite. Radiografias do tórax: discreto aumento da área de projeção frontal do coração com predominância do ventriculo esquerdo. Radiografias do crânio: processo de osteocondensação difusa generalizada com alargamento do tecido diplóico. Perimielografia: retenção parcial e duradoura do contraste na altura de $\mathbf{T}_{-}-\mathrm{T}_{7}$, sob a forma de fita irregular. Exame elétrico dos membros inferiores: sindrome de degenerescência absoluta no território muscular do nervo ciático popliteo externo bilateralmente; sindrome de degenerescência completa no território de ambos os nervos ciáticos e do nervo ciático popliteo interno à esquerda; sindrome de degenerescência parcial no território do nervo ciático poplíteo interno à direita; hipoexcitabilidade farádica e galvânica no território do nervo crural bilateralmente. Pesquisa de sangue nas fezes fortemente positiva. Exame hematológico: 6.200 .000 hemácias por $\mathrm{mm}^{3}$; hemoglobina $17,5 \mathrm{~g} \%=109 \% ; 21.000$ leucócitos por $\mathrm{mm}^{3}$. Hematócrito $65 \%$. Tempo de coagulaçáo 11 minutos; tempo de sangria 3 minutos. Mielograma: anaplasia granulocitica, aumento de eosinófilos; hiperplasia relativa da série vermelha com maturação conservada; megacariócitos presentes, normais. Volemia $(20 \mathrm{~min})$ : plasma $2.591 \mathrm{ml}$; glóbulos $5.411 \mathrm{ml}$; sangue total $7.002 \mathrm{ml}$.

Êste caso apresentava sintomatologia medular e radicular, cuja causa não nos foi possivel elucidar. A xantocromia liquórica permite considerar a possibilidade de depender a paraplegia motora e sensitiva de uma malformação vascular acompanhada de aracnoidite revelada pela perimielografia; seria esta uma correspondência intra-raquidiana dos hemangiomas por vêzes encontrada na fossa posterior na vigência de policitemias. Todavia, trata-se de mera hipótese que não foi comprovada por falta de elementos que justificassem uma exploração neurocirúrgica.

Caso 8 - N. H., sexo masculino, 49 anos, branco, brasileiro, internado no Serviço de Hematologia (Dr. Michel Jamra), em julho de 1954 (reg. 383.615). O paciente sofrera, em 1950, um icto precedido de cefaléia muito pronunciada, escurecimento da visão, estado vertiginoso; a perda de sentidos perdurou por 12 dias; ao voltar à consciência notou dificuldade em movimentar os membros no hemicorpo esquerdo e adormecimento no hemicorpo direito; apresentava, também, distúrbios da palavra, disfagia com refluxo dos alimentos pelo nariz e diplopia; quando girava a cabeça ràpidamente tinha tonturas com desequilíbrio e queda. Nessa ocasiāo foi examinado por neurologista que verificou a existência de "distúrbios motores à esquerda, hipoestesia superficial à direita, distúrbios motores oculares e faringo-laringeos com sinal da cortina à esquerda, nistagmo horizonto-rotatório e hipotonia do músculo trapézio esquerdo"; o líquiido céfalo-raquidiano resultou inteiramente normal. Em janeiro de 1954 o paciente principiou a queixar-se de fraqueza generalizada e teve crises de nervosismo com choros imotivados. Alguns meses após passou a sentir dôres no hipocôndrio esquerdo. Exame físico: espleno e hepatomegalia; tensão arterial 130x80. Exame neurológico: aumento da base de sustentação durante a marcha, com nítido desvio para a esquerda; fôrça muscular conservada; negatividade das manobras deficitárias; coordenação muscular normal; ausência de disdiadococcinesia; hiperpassividade dos membros no hemicorpo esquerdo; reflexos profundos e superficiais normais; ausência de qualquer sinal de comprometimento piramidal; hipoestesia térmica e dolorosa no hemicorpo direito, com exceção da face; sensibilidade táctil e sensibilidades profundas normais; sindrome de Claude Bernard-Horner à esquerda; véu do pálato desviado para a direita; fundos oculares normais. Eletrencefalograma normal. Exame hematológico: 5.500 .000 hemácias por $\mathrm{mm}^{3}$; hemoglobina $16 \mathrm{~g} \%=100 \%$; valor globular 0,$9 ; 9.000$ leucócitos por $\mathrm{mm}^{3} ; 598.000$ plaquetas por $\mathrm{mm}^{3}$. Volemia: $99 \mathrm{ml}$ de glóbulos por quilo de pêso. Mielograma: aumento de eosinófilos, anaplasia granulocítica, aumento de mieloblastos basófilos, promielócitos neutrófilos e metamielócitos neutrófilos; série vermelha normoblástica; megacariócitos aumentados, em plaquetopoiese. Esplenograma: não há células mielóides, isto é, não se identifica transformação mielóide. 
Os dados anamnésticos, acrescidos dos achados do exame neurológico permitem afirmar que o icto apresentado pelo paciente em 1950 correspondeu a trombose da artéria cerebelar posterior inferior esquerda (artéria da fosseta lateral do bulbo), produzindo-se a síndrome de Wallemberg, cuja sintomatologia foi progressivamente regredindo. Contudo, ainda persistiam sinais de comprometimento do núcleo ambíguo (desvio da úvula e sínal da cortina para a direita); a sindrome de Claude Bernard-Horner, assim como o desvio da marcha para a esquerda e a hiperpassividade dêsse lado, atestavam a participação do corpo restiforme no processo; a hemi-hipoestesia térmica e dolorosa no hemicorpo direito, com exceção da face, indicava lesão do feixe espino-talâmico lateral. Na literatura que compulsamos não encontramos registro de caso algum de sindrome de Wallemberg no decurso da policitemia vera. Ainda neste caso é digna de registro a normalidade do exame do fundo de ôlho.

\section{COMENTARIOS}

A incidência de sintomatologia neurológica na policitemia vera é, como vemos, de verificação muito freqüente; segundo Chalgren e Johnson ${ }^{5}, 75 \%$ dos casos apresentam distúrbios no dominio do sistema nervoso. Êsses distúrbios podem se manifestar com sintomas focais ou sob aspectos os mais diversos - cefaléia, tonturas, sonolência, parestesias, distúrbios mentais -de modo que, com freqüência, o clínico conduz o diagnóstico para uma simples neurose. Estes sintomas gerais, sobretudo a cefaléia, acompanham a grande maioria dos casos, mesmo aquêles que apresentam sintomas focais. Tôdas as observações de policitemia vera registradas neste trabalho acompanhavam-se de fenômenos nervosos gerais, sobretudo cefaléia; dêstes casos, 5 não apresentavam sintomas neurológicos focais.

Segundo Kety ${ }^{15}$, o fluxo sangüíneo cerebral varia na razão direta da tensão arterial sistêmica e em razão inversa da resistência cérebro-vascular. Esta equação resume uma série de mecanismos de que a circulação encefálica está provida com a finalidade de evitar oscilações importantes no consumo cerebral de oxigênio; assim, elevações ou quedas da tensão arterial sistêmica determinam aumento ou diminuição da resistência cérebro-vascuiar, de forma a manter inalterado o fluxo sangüíneo cerebral e, conseqüentemente, o consumo cerebral de oxigênio. Entretanto, o fluxo sangüíneo cerebral se modificará quantitativamente nos casos em que o teor de oxi-hemoglobina no sangue circulante diminuir ou aumentar sensivelmente. Nos casos de anemias, a diminuição da hemoconcentração provocará diminuição do atrito contra as paredes do sistema vascular e, em conseqüência, diminuição da resistência cérebro-vascular e aumento do fluxo sangüíneo cerebral; à custa dêste aumento da circulação encefálica, o consumo de oxigênio no encéfalo permanece constante a despeito da queda do teor da oxi-hemoglobina circulante. Condição inversa se verifica nos casos de policitemia: quando a viscosidade sangüinea aumenta, o atrito contra as paredes dos capilares determina ele- 
vação da resistência cérebro-vascular e, conseqüentemente, queda do fluxo sangüineo cerebral. Kety ${ }^{15}$ observou, na policitemia, fluxo sangüíneo cerebral de $22 \mathrm{mil} / \mathrm{min} / 100 \mathrm{~g}$ de cérebro (normal: $54 \mathrm{ml} / \mathrm{min} / 100 \mathrm{~g}$ de cérebro), sendo êste o valor mais baixo verificado em qualquer paciente vivo. No entanto, em virtude de alta concentraçāo de oxi-hemoglobina, no encéfalo dos pacientes com policitemia são mantidas trocas normais de $\mathrm{O}_{2}$ e $\mathrm{CO}_{2}$, apesar da prcnunciada redução do fluxo sangüíneo.

Êstes dois fatôres - diminuição da velocidade sangüinea e elevação da hemoconcentração - que procuram manter constante o consumo cerebral de oxigênio, favorecem a formação de tromboses vasculares. Por outro lado, o equilibrio da circulação encefálica torna-se, nessas condições, muito instável, sofrendo repercussōes devidas às freqüentes oscilações da tensão arterial; disso resultam sintomas neurológicos gerais de anóxia, de intensidade variável.

Chalgren ${ }^{4}$, Chalgren e Johnson ${ }^{5}$, Loman e Dameshek ${ }^{18}$, Roger e Osler ${ }^{24}$ atribuem à grande pletora vascular, à estase circulatória e à hipoxia tissular a sintomatologia nervosa não focal verificada na vigência da policitemia vera. Para Christian ' os sintomas nervosos menos marcados devem ser devidos a distúrbios circulatórios temporários; em um caso anátomo-clínico, êste autor encontrou áreas de amolecimento cerebral sem lesão vascular. Winkelman e Burns ${ }^{32}$ registraram um caso de policitemia vera, com confusão mental e cefaléia, no qual a morte ocorrera por insuficiência cardíaca; o exame necroscópico evidenciou aumento do encéfalo com congestão e dilatação vascular generalizada e edema perivascular; no córtex, embora a disposição arquitetural fôsse normal, as células ganglionares apresentavam, em determinadas áreas, lesões degenerativas, sobretudo do tipo isquêmico; de modo geral, havia aumento da macroglia. Devemos salientar, todavia, que êste caso de Winkelman e Burns apresentava, juntamente com a policitemia, insuficiência cardiaca que toi a causa da morte; assim, é presumivel que a estase cerebral devida à falência do miocárdio se tenha superposto à congestão provocada pela policitemia, agravando e talvez modificando o quadro anátomo-patológico.

O exame de fundo de ôlho costuma demonstrar a participação dos vasos oculares nos distúrbios vasculares da policitemia vera. Para Duke-Elder ${ }^{11}$ a retina pode ser normal, mas, usualmente, há engorgitamento e tortuosidade das veias, enquanto que as artérias conservam-se normais; algumas vêzes êstes fenômenos são muito pronunciados e o fundo de ôlho se apresenta todo cianótico; quando a estase venosa atinge ao máximo, aparecem hemorragias juntamente com edema de papila; em um estado mais avançado podem se desenvolver tromboses das veias retinianas. $\dot{E}$ interessante assinalar que, nos 5 casos que registramos sem sinais neurológicos focais, 3 evidenciaram importantes alterações oftalmoscópicas representadas por congestão de veias retinianas; todavia, nos 3 casos com sintomas focais, não foram encontradas modificações nos fundos oculares; dêstes 3 casos, um (caso 6) apresentava seqüelas de trombose no território superficial da artéria cerebral média es- 
querda, outro (caso 8) de trombose na artéria cerebelar posterior inferior esquerda; no caso 7 a sintomatologia era exclusivamente medular. Não encontramos, na bibliografia que compulsamos, qualquer registro de caso semelhante a êste último, correspondente a lesões medulares na vigência de policitemia, embora Roger e Olmer ${ }^{24}$ façam referências à possibilidade desta sede lesional, considerando-a excepcional.

Outro aspecto que merece realce é a relação entre arteriosclerose e policitemia. Dameshek ${ }^{9}$ acredita que a arteriosclerose é mais comum em pacientes policitêmicos do que em outros indivíduos do mesmo grupo etário. Segundo Fettermann e Spitler ${ }^{13}$, a policitemia vera é usualmente acompanhada por acentuada arteriosclerose, com fibrose e espessamento das arteríolas e capilares. Assim, as alteraçōes arterioscleróticas somam-se ao aumento da viscosidade sangüinea e à redução da velocidade circulatória para favorecer o aparecimento de tromboses cerebrais.

Os acidentes vasculares cerebrais são geralmente secundários à trombose, favorecida pela diminuição da velocidade sangüínea, pela arteriosclerose e pela hemoconcentração; na maior parte das vêzes êles determinam hemiplegias, afasias e hemianestesias ${ }^{4}$. Entretanto, segundo Videbaek ${ }^{29}$ não só as tromboses, mas também as hemorragias são freqüentes na policitemia vera. Lawrence, Berlin e Huff 1i, em 263 casos de policitemia, verificaram a presença de trombose cerebral em $10 \%$ dos pacientes; Burns e Arrowsmith ${ }^{2}$ encontraram 5 casos de trombose cerebral em 68 policitêmicos; Shapiro e Peyton ${ }^{27}$ relataram um caso de hemiplegia direita por trombose da carótida em paciente com policitemia vera; Osler ${ }^{22}$ refere hemorragia da artéria meníngea média ocorrida em um caso de policitemia. Segundo Foster ${ }^{14}$, as tromboses venosas retinianas que aparecem nos estados mais avançados da moléstia, chegando a afetar a veia central, podem estender-se aos seios venosos durais.

Ao lado dessas lesões focais, ocasionadas por alterações exclusivamente vasculares trombóticas ou hemorrágicas, poderemos encontrar, nos casos em que a policitemia vera é acompanhada por tumor cerebral, angiomatoso ou não, a sintomatologia própria dessas neoplasias; assim, poderá uma sindrome de hipertensão intracraniana associar-se à sintomatologia focal peculiar à sede do tumor.

\section{RESUMO}

Neste trabalho são apresentados os 8 casos de policitemia vera internados no Hospital das Clínicas da Faculdade de Medicina da Universidade de São Paulo desde sua fundação, em 1944, até junho de 1955, sôbre um total de 147.749 pacientes.

Em todos os casos havia sintomas ou sinais imputáveis a acometimento do sistema nervoso. Em 5 pacientes os sintomas eram apenas subjetivos, 
consistindo em cefaléia, tonturas e astenia; em apenas um dêsses 5 casos há referências anamnésticas a hemiparesia transitória esquerda. Em 3 dêsses 5 casos foi registrada congestão venosa retiniana; em um o fundo de ôlho foi normal; no último êste exame não foi feito.

Nos 3 pacientes restantes, ao lado de idênticos sintomas subjetivos, havia sinais neurológicos focais. No primeiro (caso 6), havia sinais de oclusão da artéria cerebral média esquerda; no segundo (caso 7), havia paraplegia motora e sensitiva por lesão medular; o último (caso 8), apresentava os elementos constitutivos da síndrome de Wallemberg, por oclusão da artéria cerebelar póstero-inferior esquerda. Na bibliografia consultada, os autores não encontraram referência a casos semelhantes aos de suas duas últimas observações.

Referindo as hipóteses patogênicas que procuram relacionar a policitemia vera à lesões diencefálicas ou à presença de hemangioblastomas intracranianos, os autores admitem. que a ocorrência de distúrbios neurológicos na vigência da policitemia vera deve ser atribuída a diversos fatôres, destacando-se o aumento da viscosidade sangüinea, com aumento de resistência cérebro-vascular e diminuição do fluxo e velocidade do sangue no encéfalo, e a arteriosclerose, cujo desenvolvimento parece ser favorecido pela condição policitêmica.

Os autores aventam a hipótese de que a paraplegia sensitivo-motora registrada em um de seus casos (caso 7) seja devida a um angioma intraraquidiano, análogo aos tumores vasculares intracranianos que, com certa freqüência, se associam à policitemia vera.

\section{SUMMARY}

\section{Neurological symptoms of Polycythemia Vera.}

This paper reports 8 cases of Polycythemia Vera registered in the "Hospital das Clínicas da Faculdade de Medicina da Universidade de São Paulo" since 1944 till June-1955, on a total of 147,749 patients.

In all cases there were symptoms and/or signs imputable to lesions of the nervous system. In 5 of the patients the symptoms were of a subjective kind (headache, dizzyness and asthenia); in only one of these 5 cases there were anamnestic references to a transient left hemiparesis. In 3 of them the authors registered a marked retinal venous congestion; in another, the "fundus oculi" was normal; in the last case no ophtalmoscopic examination was made.

In the 3 remaining patients, besides identical subjective symptoms, there were neurologic focal signs. In the first one (case 6) there were signs of occlusion of the medium left cerebral artery; in the second (case 7) the clinical picture consisted of a sensitive-motor paraplegia; in the last one 
(case 8) the Wallemberg syndrome was manifest, indicating the occlusion of the left posterior inferior cerebelar artery.

Referring the pathogenic hypothesis which seek connections between the Polycythemia Vera and the diencephalic lesions or the existence of intracranial hemangioblastomas, the authors think that the neurologic phenomena occurring with Polycythemia Vera must be explained by various factors, especially the increased blood viscosity which increases the cerebro-vascular resistance, the lessening of the flow and speed of the blood in the brain, and the arteriosclerosis, the development of which seems to be favoured by polycythemia conditions.

The authors cast forth the hypothesis that the paraplegia found in one of their patients (case 7) must be due to an intraraquidian angioma similar to the vascular tumors which are frequently associated with Polycythemia Vera.

\section{BIBLIOGRAFIA}

1. BROWN, G. E.; GIFFIN, H. Z. - Studies of the vascular changes in cases of polycythemia vera. Am. J. Med. Sc., 171:157 (fevereiro), 1926. 2. BURNS, M. B.; ARROWSMITH, W. R. - Vascular complications of polycythemia vera. Surg. Clin. North Am., 33:1023 (agôsto), 1953. 3. CARPENTER, G.; SCHWARTZ, H.; WALKER, E. - Neurogenic polycythemia. Ann. Int. Med., 19:470 (setembro), 1943. 4. CHALGREN, W. S. - In BAKER, A. B.: Clinical Neurology. Hoeber-Harper Ed., Nova York, 1955. 5. CHALGREN, W. S.; JOHNSON, D. R. - Polycythemia vera and the nervous system. Neurology, 1:53 (janeiro), 1951. 6. CHALGREN, W. S.; JOHNSON, D. R. - Peripheral neuritis due to polycythemia vera. Minnesota Med., 34:145 (fevereiro), 1951. 7. CHRISTIAN, H. A. - The nervous symptoms of polycythemia vera. Am. J. Med. Sc., 154:547, 1917. 8. DAMESHEK, W.; HENSTELL, H. - The diagnosis of polycythemia. Ann. Int. Med., 13:1360 (fevereiro), 1940. 9. DAMESHEK, W. - Physiopathology and course of polycythemia vera as related to therapy. J.A. M.A., 142:790 (março, 18), 1950. 10. DREW, J. H.; GRANT, F. C. - Polycythemia as a neuro-surgical problem. Arch. Neurol. a. Psychiat., 54:25 (julho), 1945. 11. DUKE-ELDER, W. S. - Text-Book of Ophthalmology. The C. V. Mosby Co., St. Louis, 1941. 12. FERRARO e SHERWOOD - Cit. por CARPENTER e col. ${ }^{3}$. 13. FETTERMAN, J. L.; SPITLER, W. K. - Vascular disorders of peripheral nerves. J.A.M.A., 114:275 (junho, 8), 1940. 14. FOSTER - Cit. por DUKE ELDER ${ }^{11}$. 15. KETY, S. Circulation and metabolism of the human brain in health and disease. Am. J. Med., 8:205 (fevereiro), 1950. 16. LAWRENCE, J. H. - The control of polycythemia by marrow inhibition. J.A.M.A., 141:13 (setembro, 3), 1949. 17. LAWRENCE, J. H.; BERLIN, N. I.; HUFF, R. L. - The nature and treatment of polycythemia. Medicine, 32:323 (setembro), 1943. 18. LOMAN, J.; DAMESHEK, W. - Plethora of the intracranial venous circulation in a case of polycythemia. New Eng. J. Med., 232: 394 (abril), 1945. 19. LUCAS, W. S. - Erythremia or polycythemia with chronic cyanosis and splenomegaly. Arch. Int. Med., 10:597 (dezembro), 1912. 20. MEINER, E. - Cit. por DREW E GRANT ${ }^{10}$. 21. OPENHEIMER, B. - Cit. por DREW e GRANT '0. 22. OSLER, W. - Chronic cyanosis with polycythemia and enlarged spleen: a new clinical entity. Am. J. Med. Sc., 126:187 (agôsto), 1903. 23. POLLOCK, L. J. - A case of chorea and erythremia. J.A.M.A., 78:724 (março, 11), 1922. 24. ROGER, H.; OLMER, J. - Les Syndromes Neuro-Hematiques. Masson et Cie., Paris, 1936. 25. ROSENTHAL, N.; BASSEN, F. A. - Course of polycythemia. Arch. Int. Med., 62:903 (dezembro), 1938. 26. SCHULHOF, K.; MATTHIES, M. - Polyglobulia induced by cerebral lesions. J.A.M.A., 89:2093 (dezembro, 17), 1927. 27. SHAPIRO, S. K.; PEYTON, W. T. - Spontaneous thrombosis of the carotid arteries. 
Neurology, 4:83 (fevereiro), 1954. 28. TINNEY, W. S.; HALL, B. E.; GIFFIN, H. Z. - Central nervous manifestations of polycythemia vera. Proc. Staff Meet. Mayo Clin., 18:300 (agôsto, 25), 1943. 29. VIDEBAEK, A. - Polycythemia vera co-existing with malignant tumors, particularly hypernephromas. Acta Med. Scand., 138:239, 1950. 30. WALKER, E. - Neurogenic polycythemia. Arch. Neurol. a. Psychiat., 53:251 (março), 1945. 31. WEBER, P. - Erythremia with migraine, gout and intracardiac thrombosis. Lancet, 227:808 (outubro, 13), 1934. 32, WINKELMAN, N. W.; BURNS, M. A. - Polycythemia vera and its neuropsychiatric features. J. Nerv. a. Mental Dis., 78:587 (dezembro), 1933. 33. WOOLSEY, D. - Hemangioblastoma of cerebellum with polycythemia. J. Neurosurg., 8:447 (julho), 1951.

Clínica Neurológica. Hospital das Clinicas da Fac. Med. da Univ. de São Paulo Caixa Postal 3461 - São Paulo, Brasil. 